International Conference on Renewable Energies and Power Quality (ICREPQ'11)

Las Palmas de Gran Canaria (Spain), 13th to 15th April, 2011

\title{
DC/DC converters as linkages between photovoltaic plants and module integrated multilevel-inverters
}

\author{
G. Mehlmann ${ }^{1}$, F. Schirmer, M. Zeuß, G. Herold ${ }^{1}$ \\ ${ }^{1}$ Institute of Electrical Power Systems \\ University of Erlangen-Nuremberg \\ Cauerstr. 4 - Haus1, 91058 Erlangen (Germany) \\ Phone/Fax number: +0049913185295 29/41 e-mail: mehlmann@eev.eei.uni-erlangen.de
}

\begin{abstract}
In Europe photovoltaic plants are mainly working in parallel mains operation. Until now, the solar plants are usually grid connected via central inverter stations or via string inverters. The logical advancement of the string concept is the separate connection of each solar module to the grid. Therefore module integrated inverters or multilevel-inverters can be used. This concept has some advantages, as minimized mismatching losses and minimized DC wiring. But the circuit complexity is of course much higher. In this paper the layout and implementation of DC/DC-converters as linkages between solar modules and multilevel-inverters will be presented.
\end{abstract}

\section{Keywords}

Multilevel-inverter, DC/DC converter, MPP tracking, photovoltaic module, quasi resonant switching

\section{Background}

Usually, central inverters are used for the grid connection of large plants. The layout is cheap, as only one inverter is necessary to adapt all DC-values to the AC-grid. But high losses occur because of partial shading and different orientation of the modules $[1,2]$.

The string concept operates with one inverter per string. So, a more flexible layout of the solar plant is possible and the safeguarding against failure can be improved. But, similar to the central inverter, the efficiency decreases because of mismatching losses [1,2].

Modular plants, with ideally one small inverter per module have some more advantages. As it is possible to connect each solar module separately with the grid, each module can work in its MPP. In comparison, the common string concept has just one working point for all modules connected by the string. This working point is of course worse than the MPPs of the individual modules. So, with the separate connection of the modules it is possible to increase the feed-in and as a result the income. But contrary, as the number of necessary components is very high, the investment costs increase. Also, a simple and flexible plant layout is possible and it is easy to enlarge the plant later on. So, a convenient and low priced start up with small-sized photovoltaic plants is possible. Furthermore the implementation of diagnostic systems is easy. In the long term, the fabrication of standardized devices in high numbers is possible. The low variability of the module voltages enables a convenient layout of the power electronics $[1,2]$.

The three different concepts for the grid-connection of solar plants are illustrated in Fig. 1.

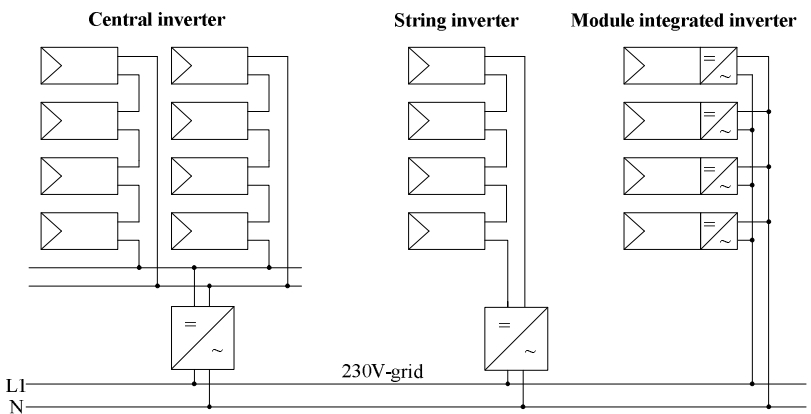

Fig. 1. Concepts for the grid connection of solar plants

The possible circuits of grid-connected self-commutating inverters are illustrated in Fig. 2. Subsequent their suitability as module integrated inverter will be discussed.

Up to now the common technology is an inverter with a power transformer. Because of the high weight and installation size of the transformer it is not usable as module integrated inverter $[1,2]$. 
The transformerless inverters, which are used for high power plants, operate with DC-voltages of at least $400 \mathrm{~V}$. So, they are only applicable for high voltage modules [2].

A strong reduction of size and weight is achievable by the use of a high frequency transformer. This circuit consists of a DC/DC converter, which feeds a DC link of about $400 \mathrm{~V}$.

Downstream is an AC inverter with cheap semiconductor switches (e.g. IGBTs, MOSFTs). The high frequency transformer is much smaller and lighter than the power transformer. A disadvantage of this concept is a higher circuit complexity because of the DC/DC converter. But altogether, the improvements in the field of power electronics allow the construction of inverters with high frequency transformers. These inverters exceed the inverters with power transformers concerning efficiency and are competitive in their manufacturing costs [2].

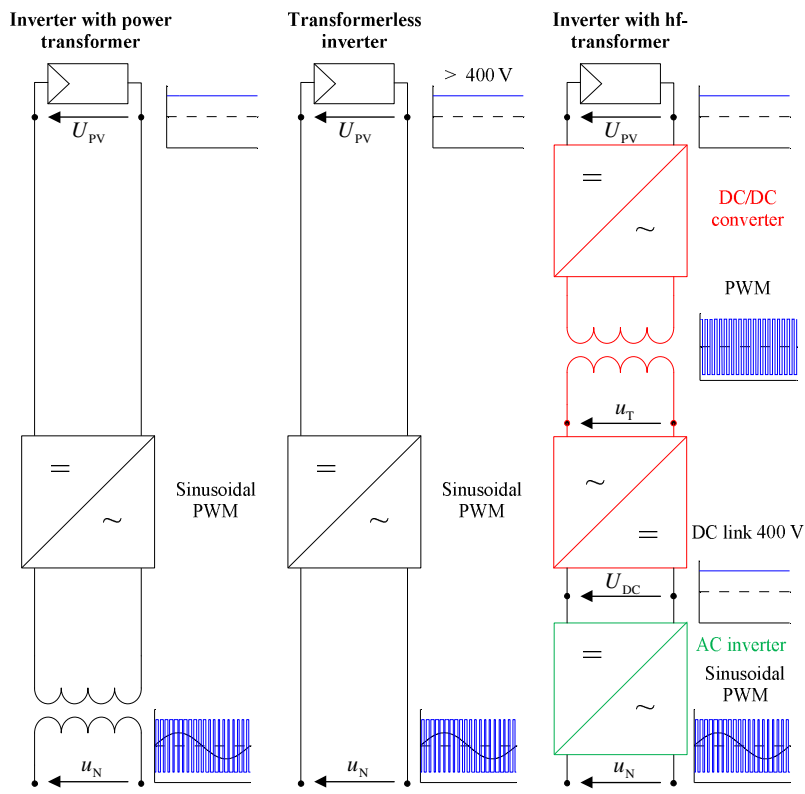

Fig. 2. Topologies of self-commutating solar inverters

\section{Approach}

An enhancement of this concept is the use of a multilevel-inverter instead of common AC inverters, for example a cascaded multilevel-inverter [3, 4].

The basic concept of a multilevel-inverter is to synthesize a staircase voltage waveform by the use of several lower voltage DC sources, as here solar modules. The voltage waveform of a multilevel-inverter is illustrated in Fig. 3.

Fig. 4 shows the associated circuit layout for two solar modules, connected to the grid via a multilevel-inverter. A multilevel-inverter has several advantages, like a high voltage quality and low electromagnetic compatibility problems. Because of the low voltages the $\mathrm{d} u / \mathrm{d} t$ stresses can be limited. As multilevel-inverters operate with lower frequencies the efficiency increases. Compared with the conventional methods of grid connection the electronic devices can be dimensioned smaller, as multiple modules generate the output voltage curve $[3,5]$.

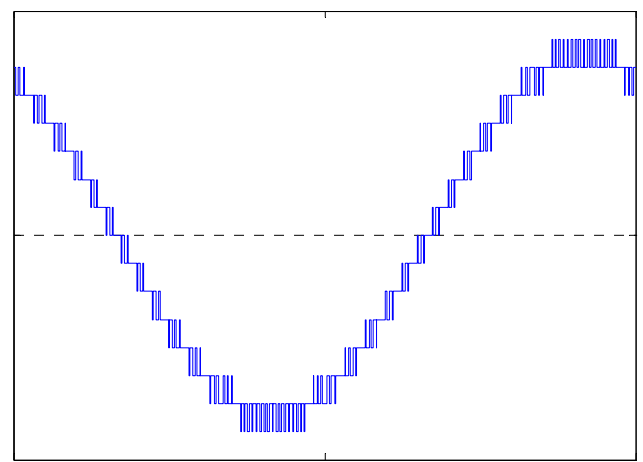

Fig. 3. Staircase voltage waveform of a multilevel-inverter Multilevel inverter with hf-transformer

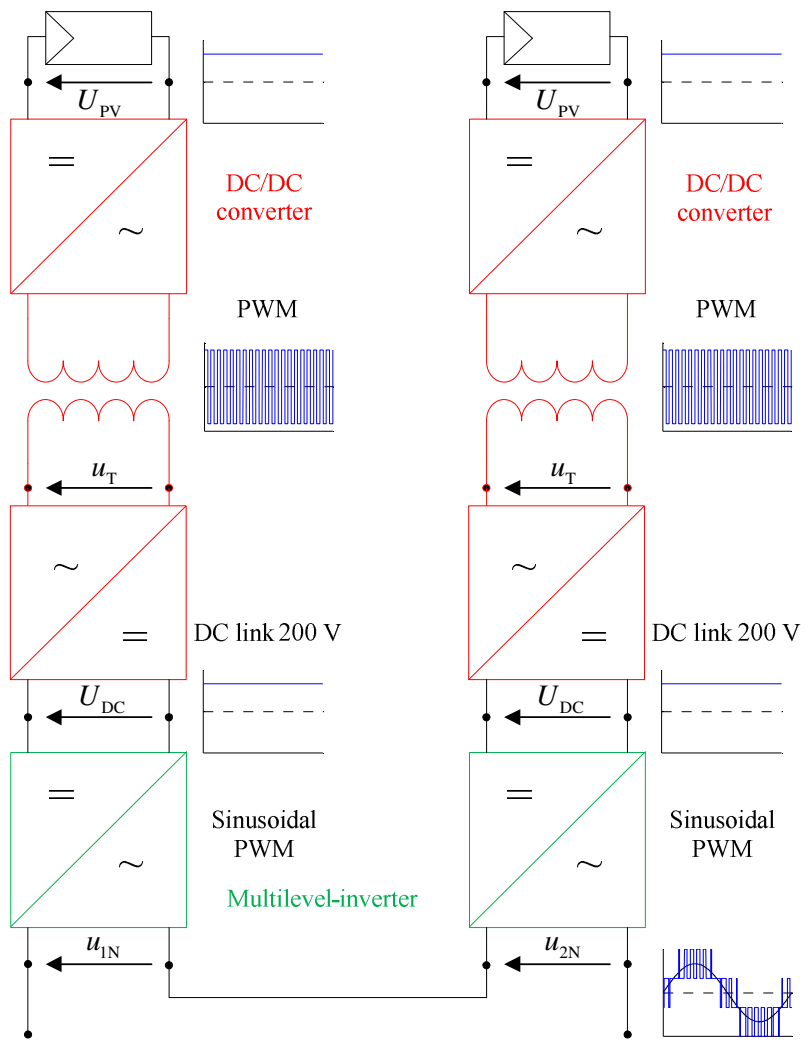

Fig. 4. Topology of a solar multilevel-inverter

In the following chapter a specific circuit will be presented based on the concept of Fig. 4.

\section{Circuit Layout}

Fig. 5 shows the circuit of a solar multilevel-inverter. The layout bases on the cascaded-multilevel-converter. Two solar modules of the same MPP voltage $U_{P V 1}$ and $U_{P V 2}$ and the same peak power are used as power supply.

Each DC/DC converter is used to generate three voltages, one per phase: $3 \times U_{s 1}$ and $3 \times U_{s 2}$.

These are the sources of the multilevel-converter.

The output terminals of the DC/DC converters are connected with H-Bridges. They are controlled in such way, that a staircase output voltage waveform emerges. Therefore they can operate at both, fundamental switching frequency (e.g. SHE) or high switching frequency (e.g. PWM, SVPWM). Per phase five output voltage levels are achievable: $0 \mathrm{~V}, \pm U_{S 1}, \pm\left(U_{S 1}+U_{S 2}\right)$. 
With each available solar module the circuit can be enlarged and the number of output voltage levels increases by two, which allows a more accurate replication of a sinusoidal waveform.

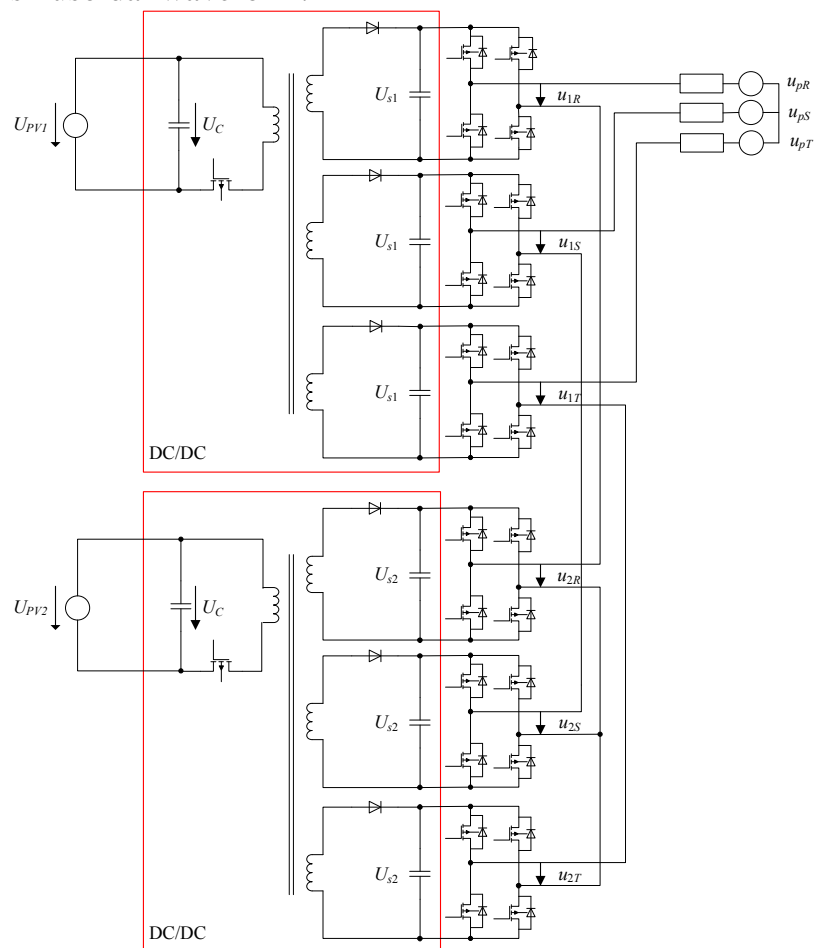

Fig. 5. Solar multilevel-inverter (5 levels)

Concerning the DC/DC converters special new requirements occur. The converters are connected in series via the multilevel-inverter and as a result not decoupled. Furthermore, the DC/DC converters have more than one fundamental task, which have to be taken into consideration. They generate the DC link voltages and are necessary for an adequate MPP tracking [6]. Here, the galvanic isolation is not only necessary because of the circuit layout. If namely a grounded person touches a module without galvanic isolation high shock currents can appear because of capacitive leakage currents $[1,7]$.

The series connection of the DC/DC converters must be considered concerning the practical implementation, the protection layout and the dimensioning of the devices. In addition, a high efficiency is important in the photovoltaic industry. So, the DC/DC converters are concerted optimized and the switching losses are reduced with quasi-resonant-switching $[8,9]$.

Usually polycrystalline solar modules have a power of about $200 \mathrm{~W}_{\text {peak }}$. So, flyback converters are suited for this concept [10].

\section{DC/DC Converter}

Fig. 6 shows two three-phase DC/DC converters, which were developed for the grid connection of solar modules via a multilevel-inverter. The DC link of each converter consists of three capacitors, one per phase.

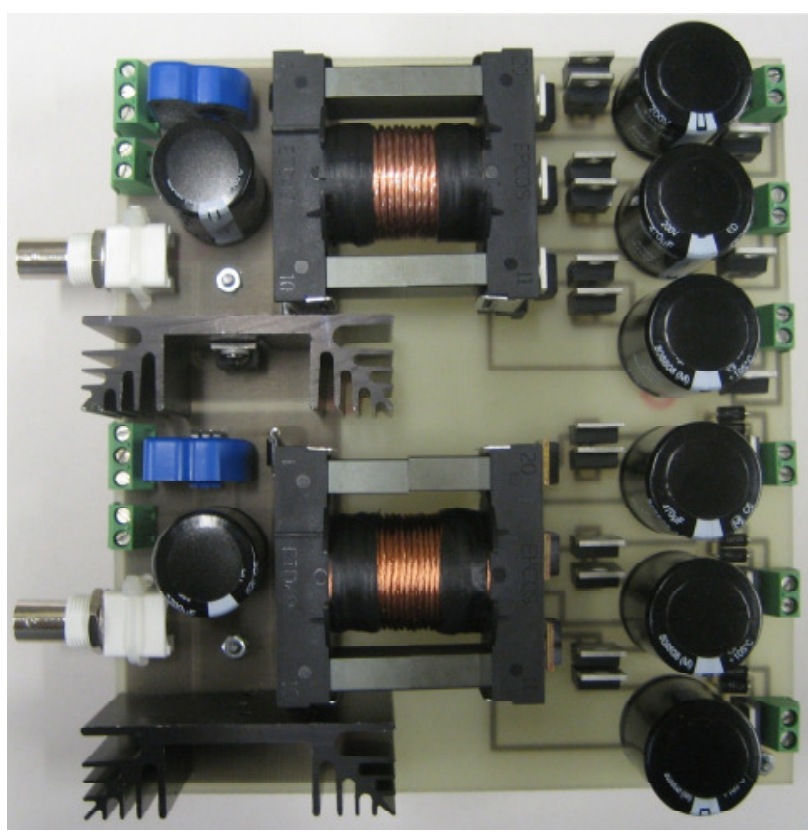

Fig. 6. DC/DC converters

\section{A. MPP-Tracking}

By variation of the duty cycle of the MOSFET of the flyback converter it is possible to control the power flow. For a maximum in-feed of the solar modules the duty cycle $\delta$ must be chosen in that way, that the load line of the converter intersects the current-voltage characteristic of the solar module in its Maximum Power Point (MPP). In equation (1) the connection of the duty cycle and the solar power is given [10].

$$
\delta=\frac{1}{U_{C}} \sqrt{\frac{2 L_{p} \cdot P_{P V}}{T}}=\frac{1}{U_{M P P}} \sqrt{\frac{2 L_{p} \cdot P_{M P P}}{T}}
$$

Because of fluctuating environmental conditions and as a result a permanently changing current-voltage characteristic of the solar module the duty cycle has to be readjust dynamically. The method for detecting the optimal working point, meaning the calculation of the correct duty cycle, is called MPP-tracking [6].

The MOSFET operates with high frequencies (here 50 $\mathrm{kHz}$ ). So the input capacitor has to decouple the direct current of the solar module and the pulsating current of the flyback converter. At this, a smoothed solar current is important to minimize oscillations around the MPP.

\section{B. Three phase operation mode}

Concerning the operation mode, a continuous power flow is important. The power flow is defined by the control of the H-bridges of the multilevel-inverter, respectively the output voltage waveform. Because of the staircase voltage waveform of the multilevel-inverter the output power is pulsed. Meaning times appear, while an output capacitor is disconnected with the grid and has no share in the power transmission. This means that in a single phase flyback converter long times appear while the converter is totally disconnected from the grid even though a continuous feed-in of its solar module is given. As a result the power has to be stored in the capacitors. So, the capacitors have to be dimensioned as large power storages. 
In a three phase flyback converter the H-bridges at the output of one converter are controlled phase shifted with $2 / 3 \pi$ and $4 / 3 \pi$. This means that the times while the converter is disconnected from the grid is much lower or ideal zero, as always at least one output capacitor is interconnected. So a continuous power transmission is possible.

Also a three phase flyback converter is self regulating. Meaning the output capacitors will be recharged as necessary. This happens because of two reasons. The conducting time of an output diode increases with decreasing output capacitor voltage. Also the amplitudes of the capacitor input currents adapt to the power requirements. Fig. 7 shows this two mechanisms by means of the capacitor input and output currents. The conduction mode of the green input current is continuous. The conduction modes of the other ones are discontinuous.

So, a three phase operation mode allows a continuous power flow which results in small capacitors. Also the capacitors work as HF-filter, which can be seen in Fig. 7 as well, by means of the smoothed output currents.

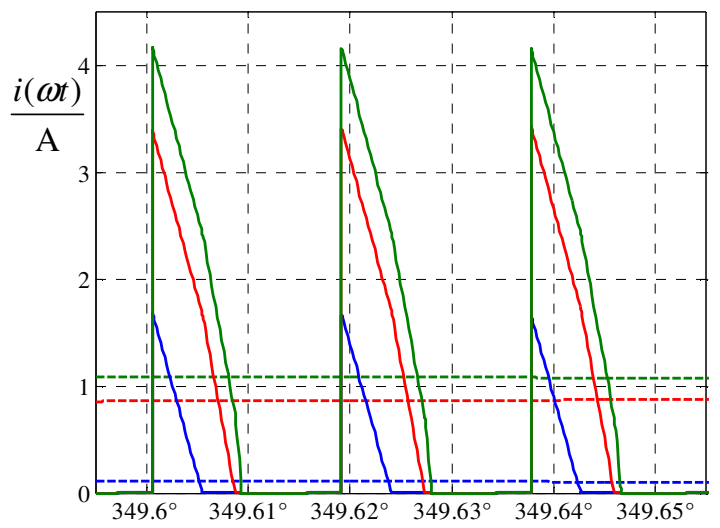

Fig. 7. Capacitor input currents (line) and output currents (dashed)

Another advantage of a three phase operation mode is the increasing power quality and the possibility to use different space phasor modulations strategies $[3,5]$.

\section{Coupled inductors}

In the case of maximum feed-in of the solar module $P_{\text {peak }}$ the converter operates at the boundary of continuous/discontinuous conduction mode (ccm, dcm). As the peak power is only reachable under laboratory conditions it is secured that the converter always operates in $\mathrm{dcm}$. As a result the reverse recovery time is always smaller than the dead time of the DC/DC converter and the MOSFET only switches on when the reverse current is already zero. This minimizes the switching losses. So, the primary inductance is defined by equation (2).

$$
L_{p}=\frac{\left(\delta \cdot U_{C}\right)^{2} T}{2 P_{\text {peak }}}=\frac{\left(\delta \cdot U_{M P P}\right)^{2} T}{2 P_{\text {peak }}}
$$

Depending on the layout, the losses of the coupled inductors vary in a wide range.

At this core losses and winding losses appear. The core losses consist of specific losses and eddy current losses.
The winding losses consist of rms, skin and proximity losses.

To reduce the losses the arrangement of the windings on the core is very important. The optimization of the transducers has many degrees of freedom and has to be done iterative. It is expedient to use HF litz wires. Depending on the current, wires have to be connected in parallel.

Here, some results are given for a peak power of $210 \mathrm{~W}$ a switching frequency of about $50 \mathrm{kHz}$ and a duty cycle of about 0,5 .

Fig. 8 shows the arrangement of the windings and the distribution of the winding losses.

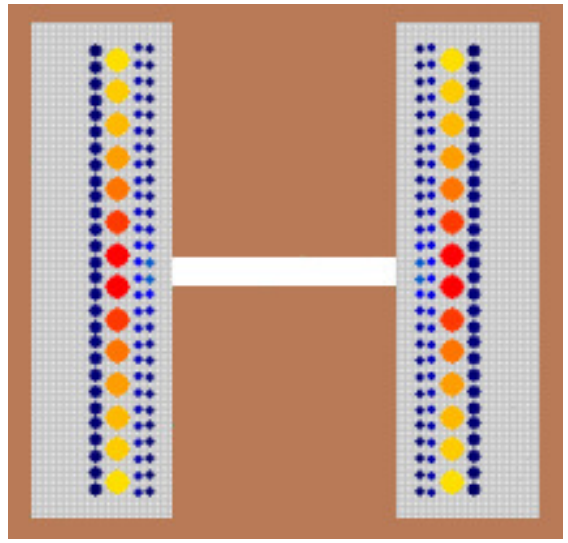

Fig. 8. Winding layout and losses

Altogether the total transducer losses are 2,44W. Fig. 9 gives an overview of the losses.

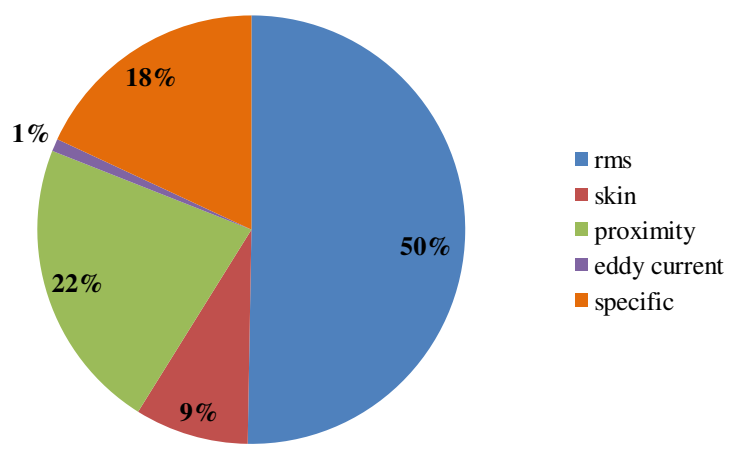

Fig. 9. Losses of the transducer

\section{Quasi-resonant-switching}

In the operation field as solar inverter a high efficiency of the DC/DC converter is important. To limit the switching losses quasi-resonant-switching of the MOSFET is used [8]. Fig. 10 shows the drain source voltage of the MOSFET. Here, a resonance phenomenon appears which reasons and positive effects will be explained in the following.

The switching sequence of the MOSFET consists of three parts. First the MOSFET switches on and the core of the transducer is magnetized. When the MOSFET switches off a transient effect appears (1). As soon as the core is demagnetized, the primary and secondary currents become zero and the diode blocks. At this another transient effect appears (2). 


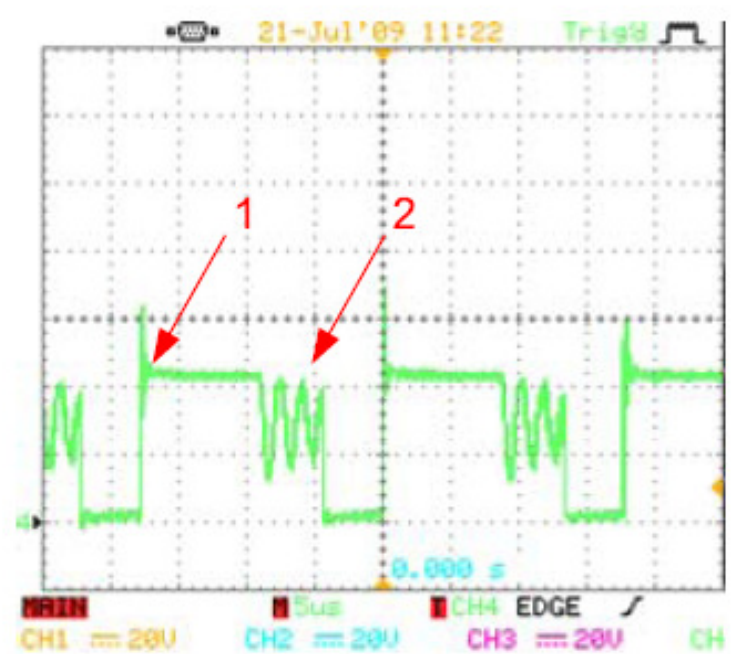

Fig. 10. Quasi-resonant-switching

Reason for this characteristic are two different resonant circuits, given in Fig. 11.

While the current commutates from the primary side to the secondary side a resonant circuit is given by $L_{\sigma}$ and $C_{M}$. This circuit is responsible for the oscillation at the beginning of the off-state (1). As $L_{\sigma}$ is small, the oscillation decays fast. The drain source voltage in the steady state is given with

$$
U_{D S}=U_{C}+\sqrt{\frac{L_{p}}{L_{s}}} \cdot U_{S} .
$$

If the flow in the core falls to zero the primary and secondary currents become zero as well and the diode blocks. The drain source voltage falls to

$$
U_{D S}=U_{C}
$$

Without a resonant circuit this change is abrupt. The resonant circuit is now defined by $C_{M}$ and $L_{p}$. As $L_{p}$ is large the frequency is low and only damped by $R_{p}$, which is defined by the electrical components (2).

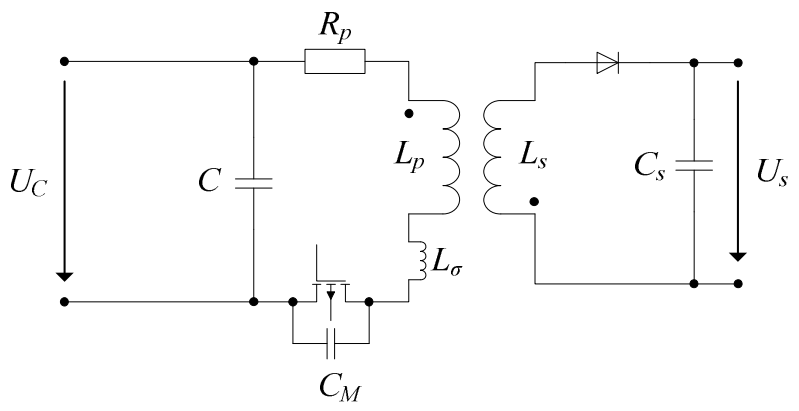

Fig. 11. Flyback converter with parasitic elements

The quasi-resonance is a positive effect. If the MOSFET is switched on exactly in an angular point of a valley ("Valley Switching"), the switching losses are minimal. In the extreme case that this voltage is zero, the switchon losses are zero ("Zero Voltage Switching"). Also, the electromagnetic radiation is lower because of valley switching, as the peak currents can be limited.

In general it is possible to make use of the quasi-resonant switching just by the parasitic elements. But also extra elements can be integrated in the circuit.

\section{E. Series Connection of DC/DC converters}

A characteristic of the use of multilevel-converters is the series connection of several DC sources. Usually DC/DC converters are parallel connected. The series connection of DC/DC converters is a specialty that could become important because of an increasing application of multilevel converters.

But concerning the layout of series connected DC/DC converters some additional requirements have to be fulfilled.

Fig. 12 shows the secondary side of two series connected DC/DC converters closed with a resistance.

In parallel with the capacitors additional free-wheeling diodes have to be installed. If namely one power supply fails, e.g. because of shading of one solar module, the associated capacitor is charged negative because of the remaining power supply. This would destroy the electrolyte capacitor. Because of the free-wheeling diode the negative voltage of a capacitor is limited to the forward voltage.

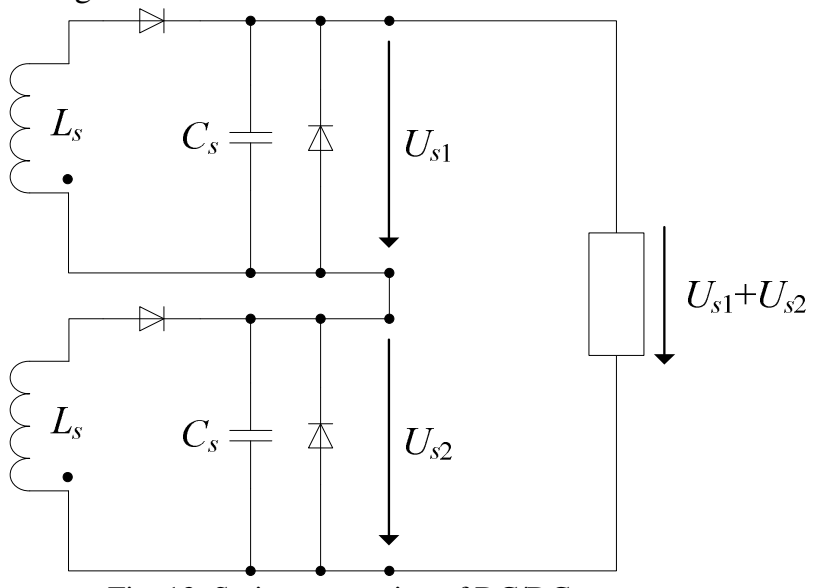

Fig. 12. Series connection of DC/DC converters

Furthermore because of the series connection the provided voltage of each DC/DC converter decreases. But the current increases, as the provided power increases. So, the current dependant losses increase, while the voltage dependant losses decrease. The higher current causes additional losses in the secondary conductors and in the diodes. As the current dependant losses outmatch the voltage dependant losses the series connection limits the total efficiency.

The efficiency of a three-phase DC/DC converter is given in equation (5).

$$
\eta=\frac{P_{o u t}}{P_{P V}}=\frac{P_{R}+P_{S}+P_{T}}{P_{M P P}}
$$

To evaluate the DC/DC converter for solar applications in Europe the European degree of efficiency has to be calculated.

The European degree of efficiency is given in equation (6).

$$
\eta_{e u}=0,03 \cdot \eta_{5 \%}+0,06 \cdot \eta_{10 \%}+0,1 \cdot \eta_{30 \%}+0,48 \cdot \eta_{50 \%}+0,2 \cdot \eta_{100 \%}
$$

Here the efficiencies for different powers are weighted with different factors, which take the radiation conditions into account. For example, the efficiency for peak power 
$\eta_{100 \%}$ which usually hardly appears in Europe has a small weighting factor of 0,2 .

For the DC/DC converters of Fig. 6 a degree of efficiency of about $96 \%$ was reached under laboratory conditions. The distribution of the losses, with reference to the elements of the converter, is given in Fig. 13.

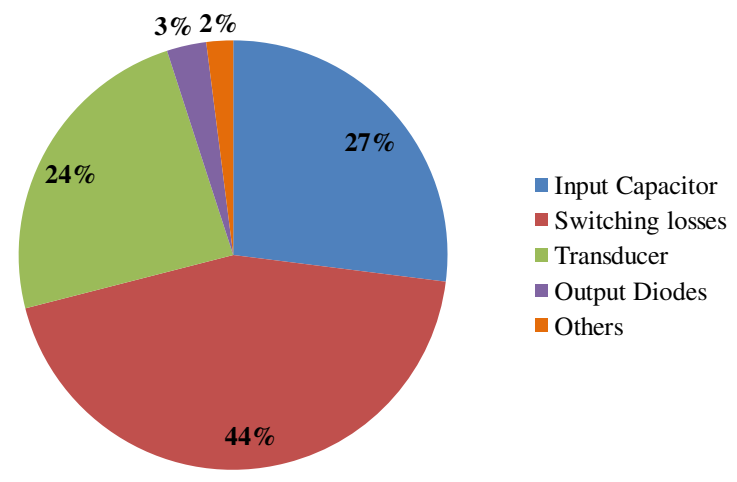

Fig. 13. Losses of one DC/DC converter

\section{Conclusion}

The increasing influence of multilevel-inverters, especially for the grid connection of renewable energies, implicates new challenges in the field of power electronics. In the context of a research project, DC/DC converters were developed. The project is the separate grid connection of solar modules via multilevel-inverters. Therefore, DC/DC converters are an essential part. Based on the concept, the DC/DC converters have to fulfill special requirements. Especially the series connection of DC/DC converters is uncommon. But also the efficiency of the converters and the generation of a symmetrical threephase system have to be considered.

Aim of the paper is to give assistance for the development of DC/DC converters for similar application areas. So, in the paper all important principles for the implementation of the DC/DC converters are explained.

\section{References}

[1] J. M. A. Myrzik and M. Calais. String and Module Integrated Inverters for Single-Phase Grid Connected Photovoltaic Systems - A Review. In Proc. IEEE PTC2003, 2003

[2] M. Viotto. Photovoltaik - Neue Horizonte, Solarmodule mit integriertem Wechselrichter. Jahrestagung des Forschungsverbunds Sonnenenergie 2003, pages 71-75, 2003

[3] S. Khomfoi and L. M. Tolbert. Power Electronics Handbook. 2. Edition. Chapter 31 - Multilevel Power Converters, Elsevier, Amsterdam, 2007

[4] G. Mehlmann. New module integrated multilevel inverter for grid connection of photovoltaic plants. ICREPQ'2010, Granada, 2010

[5] D. Grahame Holmes and Thomas A. Lipo. Pulse width modulation for power converters. John Wiley, Hoboken NJ, 2003.

[6] T. Esram and P. L. Chapman. Comparison of Photovoltaic Array Maximum Power Point Tracking Techniques. IEEE Transactions on Energy Conversion, 22(2), 2007
[7] J. C. Hernández and P. G. Vidal. Guidelines for Protection Against Electric Shock in PV Generators. IEEE Transactions on Energy Conversion, 24(1), 2009

[8] D. Schröder. Leistungselektronische Schaltungen. Springer Verlag, Heidelberg, 2008

[9] K. Liu, R. Oruganti and F. Lee. Quasi-Resonant Converters Topologies and Characteristics. IEEE Transactions on Power Electronics, 2(1), 1987

[10] U. Schlienz. Schaltnetzteile und ihre Peripherie. Vieweg, Wiesbaden, 2007 